\title{
Preliminary study of the Craniofacial Pain and Disability Inventory-11: validation for patients with head and neck cancer
}

\author{
Beatriz Serrano-García ${ }^{1}$, Isabel Bartrina-Rodríguez ${ }^{1}$, José Manuel Zubeldia-Varela ${ }^{1}$, José Luis Cebrián- \\ Carretero $^{2}$, José Luis del-Castillo-Pardo-de-Vera ${ }^{2}$, Joaquín Pardo-Montero ${ }^{3}$, Alfonso Gil-Martínez ${ }^{1,4,5}$ \\ ${ }^{1}$ Department of Physiotherapy, Centro Superior de Estudios Universitarios La Salle, Universidad Autónoma de Madrid, Spain \\ ${ }^{2}$ Maxilofacial and Oral Surgery Department, Hospital Universitario La Paz, Madrid, Spain \\ ${ }^{3}$ Motion in Brains Research Group, Centro Superior de Estudios Universitarios La Salle, Madrid, Spain \\ ${ }^{4}$ CranioSPain Research Group, Centro Superior de Estudios Universitarios La Salle, Madrid, Spain \\ ${ }^{5}$ Unit of physiotherapy, Hospital Universitario La Paz (IdiPAZ), Madrid, Spain
}

Correspondence:

PhD. Physiotherapy Department

Centro Superior de Estudios Universitarios

La Salle, Universidad Autónoma de Madrid

Calle La Salle 10, 28023 Madrid, Spain

fongilmar@gmail.com

Received: 18/02/2021

Accepted: 03/05/2021

\author{
Serrano-García B, Bartrina-Rodríguez I, Zubeldia-Varela JM, Ce- \\ brián-Carretero JL, del-Castillo-Pardo-de-Vera JL, Pardo-Montero J, et \\ al. Preliminary study of the Craniofacial Pain and Disability Invento- \\ ry-11: validation for patients with head and neck cancer. Med Oral Patol \\ Oral Cir Bucal. 2021 Sep 1;26 (5):e661-8.

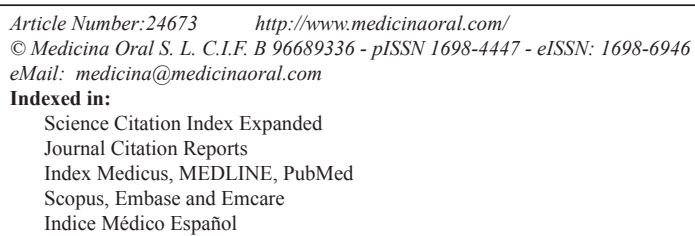

\begin{abstract}
Background: Cancer involves numerous physical, psychological and emotional changes and has a negative impact on patients. Although there are a wide variety of questionnaires for general use in patients with cancer, very few are available that assess the pain, disability and craniomandibular functionality of patients with head and neck cancer (HNC) in a more specific manner. The purpose of this study is to present the preliminary behavior of the CF-PDI in its reduced version adapted for patients with HNC.

Material and Methods: A total of 61 patients with $\mathrm{HNC}$ were included in a study to preliminarily analyze the internal consistency of the instrument, the convergent validity and the floor and ceiling effects. All the patients completed the informed consent document and a battery of 5 questionnaires: The Numerical Rating Scale (NRS), the Tampa Scale for Kinesiophobia for Temporomandibular Disorders (TSK-TMD), the Pain Catastrophizing Scale (PCS), the Quality of Life Questionnaire in patients with HNC (QLQ-HN) and the reduced version of the Craniofacial Pain and Disability Inventory (CF-PDI-11). Patients also performed 2 physical tests: measurements of the pain threshold on the masseter muscle and on the distal phalanx of the first finger; and the maximum mouth opening in neutral head position.

Results: Cronbach's $\alpha$ coefficient showed a very high internal consistency of 0.92 . In terms of convergent validity, a statistically significant correlation was found between the CF-PDI-11 and the following variables: NRS, TSKTMD, PCS, QLQ-HN, the threshold of pain in the distal phalanx of the first finger and the maximum interincisal opening. However, $21.3 \%$ of patients obtained the lowest possible score. The strongest correlation was found between the CF-PDI-11 and the QLQ-HN $(\mathrm{r}=0.85, p<0.01)$.
\end{abstract}


Conclusions: The preliminary version of the CF-PDI-11 shows that it could be a valid and reliable instrument to measure pain, disability and quality of life in patients with HNC.

Key words: Questionnaire, psychometric validation, head and neck cancer, pain, disability.

\section{Introduction}

Head and neck cancer (HNC) includes multiple functional (e.g., swallowing, speech), physical (e.g., pain, structural changes) and psychosocial (e.g., social relationships, depression, anxiety) impairments (1). Many of these types of cancer arise in the head and neck region, with numerous anatomical locations and sublocations, among which are cancer of the lip and oral cavity, nasal cavity, paranasal sinuses, nasopharynx, oropharynx, larynx, hypopharynx, salivary glands and skull base (2). HNC is the ninth most common cancer in the world (3), and is significantly more common in men (2). The main risk factors are tobacco use, alcohol consumption and viral infections, such as infection with human papillomavirus and Epstein-Barr virus, which correspond to oropharyngeal and nasopharyngeal cancer, respectively (2). Oropharyngeal cancer cases have been increasing, although with a higher survival rate, and are observed more frequently in those aged older than 50 years, with a greater number of new cases in men (4).

The loss of basic function generates disability in the patient and deterioration of their quality of life, limiting their food and drug intake as well as causing lifestyle changes, affecting their interpersonal relationships (5). Pain is typically the first symptom for consultation and is considered among cancer patients the alarm signal for which they go to the doctor. There is a broad symptomatology depending on the affected area, with underdiagnosed and undertreated pain (in different varieties and intensities) very present in all of them (6). Pain is typically a multifactorial experience, which complicates efforts to achieve adequate pain relief. Advanced HNC stages are often associated with pain, nerve damage and/or impaired function (7). Neuropathic pain is the most prevalent type in patients with cancer (8).

There is evidence of a significant association between psychological factors and cancer, with fear being a common problem among these patients. Furthermore, a strong association between poor quality of life and disability has been observed with higher levels of fear. Along these lines, an association was found between age, the presence and severity of physical symptoms (fatigue, pain and adverse effects of treatment) and certain psychological symptoms (anguish, anxiety and depression) (9). In addition, catastrophizing magnifies the severity and impact of pain as well as increases the fear of treatment failure, and a relationship between catastrophizing, depression and pain has been demonstrated (10).

Currently, there is a shortage of questionnaires in Spanish that assess pain, disability, and craniomandibular functionality in patients with $\mathrm{HNC}$ in a more specific manner, such as the Craniofacial Pain and Disability Inventory (CF-PDI) (11). However, its original design was focused on patients with chronic temporomandibular disorders and headaches. It is therefore necessary to develop new valid and reliable Spanish tools to specifically evaluate patients with HNC.

The purpose of this study is to present the preliminary behavior of the CF-PDI in its reduced version adapted for patients with HNC.

\section{Material and Methods}

\section{- Design}

The study employed a preliminary validation design of the short version of the Craniofacial Pain and Disability Inventory (CF-PDI-11) for patients with HNC. This design aimed to verify the psychometric characteristics of the questionnaire in an initial sample of 61 patients from the Medical Oncology and Maxillofacial Surgery Department at La Paz University Hospital (LPUH).

The study followed the ethical procedures according to the rules of the Declaration of Helsinki and has the acceptance of the LPUH Ethics Committee for Research with Drugs (code: PI-1923). All patients signed the informed consent document before their inclusion.

- Sample description

The inclusion criteria were age older than 18 years and being diagnosed with primary $\mathrm{HNC}$ by a medical specialist. The exclusion criteria were presenting a traumatic history causing craniofacial pain, chronic craniofacial pain of another etiology, impossibility or difficulty in understanding the questionnaires, pregnancy, patients diagnosed with cancer other than HNC or a diagnosis of neurological diseases, chronic systemic diseases or previous rheumatic diseases.

- Procedure

After selecting the patients by means of a consecutive sampling, they were provided with all the necessary information and the informed consent was signed. A battery of questionnaires was completed and 2 physical examinations were performed. This battery of questionnaires included a sociodemographic information sheet and 5 evaluation questionnaires: the Numerical Rating Scale (NRS) (12), the Tampa Scale for Kinesiophobia 
for Temporomandibular Disorders (TSK-TMD) (13), the Pain Catastrophizing Scale (PCS) (14), the Quality of Life Questionnaire for patients with HNC (QLQ-HN) (15) and the CF-PDI-11 (Supplement 1). All the questionnaires, with simple closed-ended items, were selfadministered. The physical tests consisted of pressure pain threshold measurements and maximum interincisal opening.

- Description of the instruments

Pain intensity: To measure pain intensity, the NRS was used, which consists of a $10-\mathrm{cm}$ line, with values from 0 to 10: 0 represents "no pain", and 10 "the worst pain imaginable" (12).

Kinesiophobia: The TSK-TMD assesses the fear of relapse of an injury in the craniomandibular area due to movement. Composed of 11 items, it consists of 2 factors: avoidance of activity and harm. It has been shown to have reliable psychometric characteristics (13).

Catastrophism: The PCS in its Spanish version seeks to measure the degree of catastrophizing associated with pain. It consists of 13 items and assesses 3 factors: rumination, magnification and hopelessness. Lower scores indicate less catastrophizing. It has been shown to have acceptable psychometric characteristics (14).

Quality of life: The QLQ-HN is one of the QLQCore-30 specific HNC modules used by the European Organization for Research and Treatment of Cancer. It consists of 35 items, with higher scores corresponding to a poorer quality of life. It presents 3 subscales, directed to the functionality, symptoms and global condition of the patient (15).

Development of the reduced version CF-PDI-11: The original CF-PDI consists of 21 items, with 4 multiplechoice responses, evaluating the factors of pain, craniofacial disability and functionality during activities of daily living (11). For this preliminary analysis of the CF-PDI-11, a reduced 11-item version of the original CF-PDI was employed.

To achieve the definitive reduced version, a panel of experts with experience in the development and validation of questionnaires in the field of pain and experts in cancer pain was created. The reduced version is made up of 11 items, having discarded some items from the original version (Supplement 1). The criteria for discarding the items were those questions that could not be answered by patients with $\mathrm{HNC}$ or that did not make clinical sense for these patients.

Pressure pain thresholds: Pain thresholds were measured in 2 locations: on the masseter muscle of the affected side $(1.5 \mathrm{~cm}$ distal to the zygomatic arch and 2.5 $\mathrm{cm}$ anterior to the tragus) and on the first finger (dorsal part of the distal phalanx). A digital algometer (Wagner FDX 25) with an area of $1 \mathrm{~cm}^{2}$ was used, applying it with a pressure increase of $0.5 \mathrm{Kg} / \mathrm{cm}^{2} / \mathrm{seg}$ and perpendicularly (16). Three measurements were made with an interval of 30 seconds as indicated in previously described protocols (17).

Maximum interincisal opening: The maximum oral opening was measured in the neutral position of the head while recording the maximum opening measured from the lower edge of the upper incisors to the upper edge of the lower incisors (18).

- Statistical analysis

The statistical analysis was performed using the SPSS statistical program, version 20.0. The KolmogorovSmirnov test (over 50 participants) was used to verify the normal distribution of the variables. Descriptive statistics were presented as mean and standard deviation and maximum-minimum range for quantitative variables. The qualitative variables were presented by frequency and percentage. The statistical inference used to check the psychometric properties was performed using the following tests: (a) for reliability, internal consistency of the instrument was analyzed with Cronbach's $\alpha$ and the total correlation of items. Adequate internal consistency was considered when Cronbach's $\alpha$ was $\geq 0.70$; (b) convergent validity between the CF-PDI-11 questionnaire and the TSK-TMD, PCS, QLQ-HN and its 3 subscales was assessed with Pearson's correlation coefficient. The following correlations were considered: very weak between 0 and 0.3 ; moderate between 0.31 and 0.59 ; and strong from 0.60 ; (c) the ceiling and floor effects were analyzed according to the percentage of patients with the lowest (floor) and highest (ceiling) score in each dimension, considering that they are present if more than $15 \%$ of those surveyed achieved this score. Values of $p<0.05$ were considered statistically significant. The confidence interval was estimated at $95 \%$.

\section{Results}

- Description of the study sample

The sample consisted of 61 patients diagnosed with $\mathrm{HNC}$ with a mean age \pm standard deviation of $60.5 \pm$ 12.5 years. The percentage of men was $67.2 \%$ of the sample. Regarding the level of study achieved by our patients, $6.6 \%$ had no previous studies, $21.3 \%$ primary studies, $34.4 \%$ secondary studies, $36.1 \%$ university studies and $1.6 \%$ data lost.

Regarding the treatment received for cancer, $49.2 \%$ did not receive any treatment, $19.7 \%$ received radiotherapy and $26.2 \%$ received radiotherapy plus chemotherapy. Related to employment status, $15 \%$ were active, $16.7 \%$ unemployed, $46.7 \%$ retired and $21.7 \%$ on leave due to disability. The descriptive statistics are shown in Table 1.

- Internal consistency

Cronbach's $\alpha$ coefficient presented a value of 0.92 , showing a very high internal consistency. All the data related to the internal consistency of the questionnaires are presented in Table 2. 
Table 1: Descriptive statistics and estimates of internal consistency.

\begin{tabular}{|c|c|c|c|}
\hline Instrument & Mean \pm SD & Range [max-min] & Alpha Cronbach \\
\hline $\begin{array}{l}\text { CF-PDI11 } \\
(\mathbf{N}=\mathbf{6 1})\end{array}$ & $7.57 \pm 8.12$ & $0-29$ & 0.92 \\
\hline $\begin{array}{l}\text { NRS } \\
(\mathbf{N}=\mathbf{6 1})\end{array}$ & $1.49 \pm 2.30$ & $0-8$ & - \\
\hline $\begin{array}{l}\text { TSK-TDM } \\
(\mathbf{N}=\mathbf{6 1 )}\end{array}$ & $20.33 \pm 9.16$ & $11-41$ & 0.91 \\
\hline $\begin{array}{l}\mathrm{PCS} \\
(\mathrm{N}=6 \mathbf{6 1})\end{array}$ & $8.66 \pm 12.03$ & $0-49$ & 0.96 \\
\hline $\begin{array}{l}\text { QLQ SubTotal1 } \\
(\mathbf{N}=\mathbf{6 1})\end{array}$ & $31.74 \pm 9.84$ & $18-57$ & 0.94 \\
\hline $\begin{array}{l}\text { QLQ SubTotal2 } \\
(\mathbf{N}=\mathbf{6 1})\end{array}$ & $20.34 \pm 9.29$ & $10-46$ & 0.94 \\
\hline $\begin{array}{l}\text { QLQ SubTotal3 } \\
(\mathbf{N}=\mathbf{6 1}) \\
\end{array}$ & $6.59 \pm 1.16$ & $5-9$ & 0.94 \\
\hline $\begin{array}{l}\text { QLQ Total } \\
(\mathbf{N}=\mathbf{6 1})\end{array}$ & $58.67 \pm 18.94$ & $35-110$ & 0.94 \\
\hline $\begin{array}{l}\text { PPT Masseter } \\
(\mathbf{N}=\mathbf{3 6})\end{array}$ & $2.41 \pm 1.15$ & $0.68-5.75$ & - \\
\hline $\begin{array}{l}\text { PPT } 1^{\text {st }} \text { finger distal phalanx } \\
(\mathbf{N}=\mathbf{3 6})\end{array}$ & $6.23 \pm 2.11$ & $2.58-10.84$ & - \\
\hline $\begin{array}{l}\text { Maximum interincisal opening } \\
(\mathbf{N}=\mathbf{3 6})\end{array}$ & $41.36 \pm 8.54$ & $19-57.7$ & - \\
\hline
\end{tabular}

CF-PDI11, short version of the Craniofacial Pain and Disability Inventory; NRS, Numeric Rating Scale; TSK-TMD, Tampa Scale of Kinesiophobia for Temporomandibular Disorders; PCS, Pain Catastrophizing Scale; QLQ SubTotal1, Quality of Life Questionnaire for patients with HNC subscale 1; QLQ SubTotal2, Quality of Life Questionnaire for patients with HNC subscale 2; QLQ SubTotal3, Quality of Life Questionnaire for patients with HNC subscale 3; QLQ Total, Quality of Life Questionnaire for patients with HNC; PPT, Pressure Pain Threshold.

Table 2: Corrected item-total between CF-PDI11 items.

\begin{tabular}{|c|c|c|c|c|c|}
\hline $\begin{array}{c}\text { CF-PDI1 } \\
\text { item }\end{array}$ & $\begin{array}{c}\text { Scale mean if } \\
\text { item deleted }\end{array}$ & $\begin{array}{c}\text { Scale variance if } \\
\text { item deleted }\end{array}$ & $\begin{array}{c}\text { Corrected item- } \\
\text { total correlation }\end{array}$ & $\begin{array}{c}\text { Squared multiple cor- } \\
\text { relation }\end{array}$ & $\begin{array}{c}\text { Cronbach's alpha } \\
\text { if item deleted }\end{array}$ \\
\hline 1 & 6.90 & 55.35 & 0.70 & 0.76 & 0.91 \\
\hline 2 & 7.12 & 55.87 & 0.76 & 0.76 & 0.91 \\
\hline 3 & 6.63 & 54.00 & 0.68 & 0.61 & 0.91 \\
\hline 4 & 7.23 & 56.18 & 0.79 & 0.77 & 0.91 \\
\hline 5 & 7.27 & 55.86 & 0.78 & 0.73 & 0.91 \\
\hline 6 & 7.03 & 53.96 & 0.76 & 0.65 & 0.91 \\
\hline 7 & 7.03 & 54.17 & 0.83 & 0.75 & 0.90 \\
\hline 8 & 7.02 & 54.90 & 0.70 & 0.58 & 0.91 \\
\hline 9 & 6.65 & 56.37 & 0.56 & 0.49 & 0.92 \\
\hline 10 & 7.20 & 57.82 & 0.71 & 0.59 & 0.91 \\
\hline 11 & 6.92 & 52.18 & 0.57 & 0.56 & 0.92 \\
\hline
\end{tabular}

CF-PDI11, short version of the Craniofacial Pain and Disability Inventory.

- Convergent validity

Convergent validity was assessed with Pearson's correlation coefficient. For this, the CF-PDI-11 was correlated with the TSK-TMD, PCS, QLQ-HN and its 3 subscales. All the data obtained statistically significant correlations with the CF-PDI-11. The strongest correlation was found between the CF-PDI-11 and the QLQ-HN ( $\mathrm{r}=0.85 ; p<0.01)$. The CF-PDI-11 was also significantly correlated with the pressure pain threshold, the maximum interincisal opening and the NRS, but not between the CF-PDI-11 and the pressure pain threshold in the masseter $(\mathrm{r}=-0.26$; $\mathrm{p}>0.05)$. All the correlation data are presented in Table 3 and Table 4. 
Table 3: Pearson's Correlation Coefficient of our main scales (convergent validation).

\begin{tabular}{|c|c|c|c|c|c|c|c|c|c|c|c|}
\hline & $\stackrel{\mathscr{a}}{z}$ & 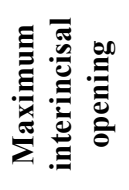 & 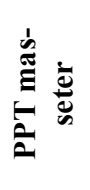 & 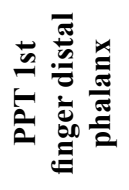 & $\sum_{\substack{1 \\
\frac{1}{6}}}$ & $\bigcup_{2}^{\infty}$ & $\stackrel{0}{\overline{0}} \overline{\bar{B}}$ & $\stackrel{O}{0} \frac{N}{0}$ & $\stackrel{0}{0} \stackrel{0}{=}$ & 웜 & $\underset{\Xi}{\bar{a}}$ \\
\hline $\begin{array}{l}\text { NRS } \\
N=61\end{array}$ & 1 & -0.18 & -0.22 & -0.32 & $0.41^{* *}$ & $0.65^{* *}$ & $0.60^{* *}$ & $0.59^{* *}$ & $0.55^{* *}$ & $0.63^{* *}$ & $0.76^{* *}$ \\
\hline $\begin{array}{l}\text { Maximum interinci- } \\
\text { sal opening } N=36\end{array}$ & & 1 & 0.02 & -0.08 & $-0.60^{* *}$ & -0.31 & -0.23 & $-0.53^{* *}$ & -0.21 & -0.40 & $-0.43^{* *}$ \\
\hline $\begin{array}{l}\text { PPT masseter } \\
\mathrm{N}=36\end{array}$ & & & 1 & $0.52^{* *}$ & -0.07 & -0.19 & -0.23 & -0.23 & -0.08 & -0.24 & -0.26 \\
\hline $\begin{array}{l}\text { PPT 1st finger distal } \\
\text { phalanx } \\
\mathrm{N}=36\end{array}$ & & & & 1 & 0.03 & $-0.30^{* *}$ & -0.35 & -0.37 & $-0.18^{* *}$ & -0.38 & -0.39 \\
\hline $\begin{array}{l}\text { TSK-TMD } \\
\mathrm{N}=61\end{array}$ & & & & & 1 & 0.62 & $0.42^{* *}$ & $0.49^{* *}$ & 0.32 & $0.48^{* *}$ & $0.58^{* *}$ \\
\hline $\begin{array}{l}\text { PCS } \\
\mathrm{N}=61\end{array}$ & & & & & & 1 & $0.60^{* *}$ & 0.64 & 0.41 & $0.65^{* *}$ & 0.70 \\
\hline $\begin{array}{l}\text { QLQ Sub1 } \\
\mathrm{N}=61\end{array}$ & & & & & & & 1 & 0.82 & 0.53 & $0.95^{* *}$ & 0.81 \\
\hline $\begin{array}{l}\text { QLQ Sub2 } \\
\mathrm{N}=61\end{array}$ & & & & & & & & 1 & 0.47 & $0.95^{* *}$ & $0.80^{* *}$ \\
\hline $\begin{array}{l}\text { QLQ Sub3 } \\
\mathrm{N}=61\end{array}$ & & & & & & & & & 1 & $0.57^{* *}$ & 0.57 \\
\hline $\begin{array}{l}\text { QLQ TOTAL } \\
\mathrm{N}=61\end{array}$ & & & & & & & & & & 1 & $0.85^{* *}$ \\
\hline $\begin{array}{l}\text { IDD-CF11 } \\
\mathrm{N}=61\end{array}$ & & & & & & & & & & & 1 \\
\hline
\end{tabular}

$* p<0.05 ; * * p<0.01$

CF-PDI11, short version of the Craniofacial Pain and Disability Inventory; NRS, Numeric Rating Scale; TSK-TMD, Tampa Scale of Kinesiophobia for Temporomandibular Disorders; PCS, Pain Catastrophizing Scale; QLQ SubTotal1, Quality of Life Questionnaire for patients with HNC subscale 1; QLQ SubTota12, Quality of Life Questionnaire for patients with HNC subscale 2; QLQ SubTotal3, Quality of Life Questionnaire for patients with HNC subscale 3; QLQ Total, Quality of Life Questionnaire for patients with HNC; PPT, Pressure Pain Threshold.

Table 4: Correlation matrix inter-elements CF-PDI11.

\begin{tabular}{|c|c|c|c|c|c|c|c|c|c|c|c|}
\hline $\begin{array}{c}\text { CF-PDI11 } \\
\text { item }\end{array}$ & $\mathbf{1}$ & $\mathbf{2}$ & $\mathbf{3}$ & $\mathbf{4}$ & $\mathbf{5}$ & $\mathbf{6}$ & $\mathbf{7}$ & $\mathbf{8}$ & $\mathbf{9}$ & $\mathbf{1 0}$ & $\mathbf{1 1}$ \\
\hline $\mathbf{1}$ & 1 & $0.67^{* *}$ & $0.50^{* *}$ & $0.75^{* *}$ & 0.54 & $0.65^{* *}$ & $0.66^{* *}$ & $0.47^{* *}$ & 0.37 & $0.63^{* *}$ & $0.54^{* *}$ \\
\hline $\mathbf{2}$ & & 1 & $0.45^{* *}$ & $0.57^{* *}$ & $0.76^{* *}$ & 0.69 & $0.67^{* *}$ & $0.52^{* *}$ & $0.39^{* *}$ & 0.67 & $0.61^{* *}$ \\
\hline $\mathbf{3}$ & & & 1 & $0.55^{* *}$ & $0.58^{* *}$ & $0.53^{* *}$ & 0.66 & $0.48^{* *}$ & $0.66^{* *}$ & $0.48^{* *}$ & 0.52 \\
\hline $\mathbf{4}$ & & & & 1 & $0.59^{* *}$ & $0.67^{* *}$ & $0.68^{* *}$ & 0.57 & $0.44^{* *}$ & $0.56^{* *}$ & $0.74^{* *}$ \\
\hline $\mathbf{5}$ & & & & & 1 & $0.62^{* *}$ & $0.70^{* *}$ & $0.65^{* *}$ & $0.44^{* *}$ & $0.64^{* *}$ & $0.68^{* *}$ \\
\hline $\mathbf{6}$ & & & & & & 1 & $0.72^{* *}$ & $0.53^{* *}$ & $0.39^{* *}$ & $0.58^{* *}$ & $0.63^{* *}$ \\
\hline $\mathbf{7}$ & & & & & & & 1 & $0.68^{* *}$ & $0.57^{* *}$ & $0.58^{* *}$ & $0.67^{* *}$ \\
\hline $\mathbf{8}$ & & & & & & & & 1 & $0.47^{* *}$ & $0.55^{* *}$ & $0.71^{* *}$ \\
\hline $\mathbf{9}$ & & & & & & & & & 1 & $0.34^{* *}$ & $0.40^{* *}$ \\
\hline $\mathbf{1 0}$ & & & & & & & & & & 1 & $0.70^{* *}$ \\
\hline $\mathbf{1 1}$ & & & & & & & & & & & 1 \\
\hline
\end{tabular}

$* p<0.05 ; * * p<0.01$

CF-PDI11, short version of the Craniofacial Pain and Disability Inventory.

- Floor and ceiling effect

No ceiling effect was identified in our sample; however, $13(21.3 \%)$ of the 61 patients obtained the lowest possible score ( 0 points). The minimum and maximum ranges reported by the patients were 0 and 29 points, respectively. 


\section{Discussion}

The present study was designed to develop the reduced draft version of the CF-PDI-11 for patients with HNC. Specifically, internal consistency, floor and ceiling effect, as well as convergent validity were evaluated, demonstrating a fast, reliable instrument, without ceiling effect and with good convergent validity. It is an inventory that can be validated internationally, given it does not contain items specifically related to Spanish culture.

The study design had a biopsychosocial approach, because patients with $\mathrm{HNC}$ can present social and psychological factors caused by the anxiety related to their symptoms, diagnosis and the adverse effects of the treatment. The development of various inventories and questionnaires, such as the Cancer Needs Distress Inventory (19), in which the anguish of cancer patients is evaluated, or the Anxiety and Depression Scale (20), show that risk factors for depression throughout the evolution of the disease are related to the personality of the patient.

Various questionnaires are available to evaluate oncology patients in general; however, very few are specific for patients with HNC. Furthermore, a large number of the existing questionnaires are not validated in Spanish. Reviewing the available literature, we found certain questionnaires related to quality of life, such as the Functional Assessment of Cancer Therapy, Head and Neck (21) and the Oral Health Impact Profile-14 (22) as well as the Liverpool Oral Rehabilitation Questionnaire (23), which focuses on the impact of rehabilitation in these patients. On the other hand, the Brief Core Set Questionnaire (24), which is the reduced version of the University of Washington Quality of Life Questionnaire (25), is validated in Spanish; however, it is an excessively long questionnaire compared with the CFPDI-11. Regarding disability, we found the Carcinologic Handicap Index (26), and in relation to patient concerns, we found the Patient Concerns Inventory-Head and Neck (27). Therefore, the CF-PDI-11 could be the first reduced instrument in Spanish to assess some factors related to patients suffering from HNC.

Our sample consisted of a higher percentage of men $(67.2 \%)$, which coincides with the literature that shows a higher prevalence in males. This higher prevalence could be associated with a greater amount of substance abuse by men, such as alcohol and tobacco, although the HNC caused by this is decreasing due to increasing awareness of the harmful health effects of these substances (28). On the other hand, the overall rate of HNC is increasing due to the human papilloma virus due to the sexual behaviors of the population, with an increase in oral sex and the number of sexual partners. This would not fully explain the higher prevalence in men. On the other hand, $49.2 \%$ of the patients were not receiv- ing treatment, given their recruitment was performed prior to treatment initiation. We should therefore consider that the literature indicates that both pain and disability often manifest themselves after the completion of treatment in these patients (29).

- Associations

The CF-PDI-11 showed important associations with other questionnaires and tests performed, except in the pressure pain threshold on the masseter muscle. The majority of these associations was observed between the CF-PDI-11 and the QLQ-HN in quality of life. It should be considered that beyond the mortality that patients with $\mathrm{HNC}$ present, quality of life is by far the most valued variable (15), which is clinically key in these patients' perception of well-being.

A strong association with fear has also been observed. This fear is especially present in the young population, in those who are undergoing complex surgery, chemotherapy or radiotherapy treatments and in those who in most cases believe that there will be a recurrence at some point in their life; so much so, that there are even specific questionnaires to assess fear of recurrence (30). - Clinical implications

In patients with $\mathrm{HNC}$, physical and psychosocial conditions of various kinds develop, with pain, disability and dysfunction throughout the evolution of the disease. Unfortunately, there is evidence of insufficient pain management in these patients; thus, the development and use of inventories such as the CF-PDI-11 are necessary to achieve a better approach by measuring and recording the variables involved in this disease.

The authors of the present work consider that the CFPDI-11 could become a valid and reliable instrument in the Spanish-speaking population to measure the variables of pain, disability, functionality and/or quality of life in patients with HNC. In addition, the CF-PDI-11 aims to cover aspects that the patient demands in a fast and efficient way, given the time of its completion is estimated at approximately 1 minute and 30 seconds. - Limitations

First, this is a preliminary study; although the development of a study with these characteristics could be promising and of interest, it has some limitations associated with the size of the sample. That is why we were unable to perform a factor analysis of the instrument. For a definitive sample size, at least 100 participants will be necessary for a factor analysis to be performed with sufficient guarantees in accordance with data stability and variability criteria. Furthermore, various authors have suggested that a sample of 10-15 participants per item might be adequate for this type of statistical analysis. In this case, 100 to 110 participants would be necessary.

On the other hand, there was no reevaluation to check the reliability of repetition by means of the Intraclass 
Correlation Coefficient by means of test-retest, given a large portion of the patients were about to begin treatment and their responses might be different after the intervention. We must also emphasize that a considerable number of patients did not want to participate in the study due to their poor general condition due to the disease itself. Also, it should be considered that the sample was made up of patients with a variety of HNCs and therefore they had differing characteristics. Cronbach's $\alpha$ coefficient was quite high in its result, which, although it is still too early to determine, could suggest the possibility of some redundant questions. Furthermore, although the study is preliminary, another limitation could be the appearance of a $21.3 \%$ floor effect. In the definitive study, it will be necessary to determine whether any of the questions did not apply to a significant part of the population and whether the selection of the sample was optimal.

Future research with a minimum sample of 100 patients would allow a factor analysis and validation of the usefulness CF-PDI-11 in patients with HNC.

\section{Conclusions}

The preliminary version of CF-PDI-11 shows that it could become a promising, valid and reliable instrument for use in patients with HNC. This preliminary questionnaire has shown a high association with the QLQ-HN of quality of life in patients with HNC. A future study with more than 100 participants is required for its final validation.

\section{References}

1. Argiris A, Karamouzis MV, Raben D, Ferris RL. Head and neck cancer. Lancet. 2008;371:1695-709.

2. Gillison ML, Chaturvedi AK, Anderson WF, Fakhry C. Epidemiology of Human Papillomavirus-Positive Head and Neck Squamous Cell Carcinoma. J Clin Oncol. 2015;33:3235-42.

3. Ferlay J, Soerjomataram I, Dikshit R, Eser S, Mathers C, Rebelo $\mathrm{M}$, et al. Cancer incidence and mortality worldwide: sources, methods and major patterns in GLOBOCAN 2012. Int J Cancer. 2015;136:E359-86.

4. Chaturvedi AK, Engels EA, Pfeiffer RM, Hernandez BY, Xiao W, $\mathrm{Kim} \mathrm{E}$, et al. Human papillomavirus and rising oropharyngeal cancer incidence in the United States. J Clin Oncol. 2011;29:4294-301.

5. Dios PD, Lestón JS. Oral cancer pain. Oral Oncol. 2010;46:448-51. 6. Ostrom QT, Gittleman H, Liao P, Rouse C, Chen Y, Dowling J, et al. CBTRUS statistical report: primary brain and central nervous system tumors diagnosed in the United States in 2007-2011. Neuro Oncol. 2014;16:iv1-63.

7. Gorsky M, Epstein JB, Oakley C, Le ND, Hay J, Stevenson-Moore P. Carcinoma of the tongue: a case series analysis of clinical presentation, risk factors, staging, and outcome. Oral Surg Oral Med Oral Pathol Oral Radiol Endod. 2004;98:546-52.

8. Epstein J, Elad S, Eliav E, Jurevic R, Benoliel R. Orofacial pain in cancer: part II-clinical perspectives and management. J Dent Res. 2007;86:506-18.

9. Simard S, Thewes B, Humphris G, Dixon M, Hayden C, Mireskandari $\mathrm{S}$, et al. Fear of cancer recurrence in adult cancer survivors: a systematic review of quantitative studies. J Cancer Surviv. 2013;7:300-22.
10. Quartana PJ, Campbell CM, Edwards RR. Pain catastrophizing: a critical review. Expert Rev Neurother. 2009;9:745-58.

11. Madrid A, Carlos RJ, La Touche R, de Estudios CS, La Salle U, la Salle C. Craniofacial pain and disability inventory (CF-PDI): development and psychometric validation of a new questionnaire. Pain Physician. 2014;17:95-108.

12. Ferreira-Valente MA, Pais-Ribeiro JL, Jensen MP. Validity of four pain intensity rating scales. Pain. 2011;152:2399-404.

13. La Touche R, Pardo-Montero J, Cuenca-Martínez F, Visscher CM, Paris-Alemany A, López-de-Uralde-Villanueva I. Cross-Cultural Adaptation and Psychometric Properties of the Spanish Version of the Tampa Scale for Kinesiophobia for Temporomandibular Disorders. J Clin Med. 2020;9:2831.

14. García Campayo J, Rodero B, Alda M, Sobradiel N, Montero J, Moreno S. Validación de la versión española de la escala de la catastrofización ante el dolor (Pain Catastrophizing Scale) en la fibromialgia. Med Clin (Barc). 2008;131:487-92.

15. López-Jornet P, Camacho-Alonso F, López-Tortosa J, Tovar TP, Rodríguez-Gonzales MA. Assessing quality of life in patients with head and neck cancer in Spain by means of EORTC QLQ-C30 and QLQ-H\&N35. J Craniomaxillofac Surg. 2012;40:614-20.

16. Rolke R, Baron R, Maier Ca, Tölle T, Treede R, Beyer A, et al. Quantitative sensory testing in the German Research Network on Neuropathic Pain (DFNS): standardized protocol and reference values. Pain. 2006;123:231-43.

17. La Touche R, Paris-Alemany A, Gil-Martínez A, Pardo-Montero J, Angulo-Díaz-Parreño S, Fernández-Carnero J. Masticatory sensory-motor changes after an experimental chewing test influenced by pain catastrophizing and neck-pain-related disability in patients with headache attributed to temporomandibular disorders. J Headache Pain. 2015;16:20

18. Beltran-Alacreu H, López-de-Uralde-Villanueva I, Paris-Alemany A, Angulo-Díaz-Parreño S, La Touche R. Intra-rater and Interrater reliability of mandibular range of motion measures considering a neutral craniocervical position. J Phys Ther Sci. 2014;26:915-20.

19. Lowery AE, Greenberg MA, Foster SL, Clark K, Casden DR, Loscalzo M, et al. Validation of a needs-based biopsychosocial distress instrument for cancer patients. Psychooncology. 2012;21:1099-106. 20. Shimizu K, Nakaya N, Saito-Nakaya K, Akechi T, Yamada Y, Fujimori M, et al. Clinical biopsychosocial risk factors for depression in lung cancer patients: a comprehensive analysis using data from the Lung Cancer Database Project. Ann Oncol. 2012;23:1973-9. 21. Bilal S, Doss JG, Cella D, Rogers SN. Quality of life associated factors in head and neck cancer patients in a developing country using the FACT-H\&N. J Craniomaxillofac Surg. 2015;43:274-80.

22. Tesic M, Cankovic M, Jevtic M, Stevanovic D. Validation of the oral health impact profile - 14 in patients with head and neck cancer. Med Oral Patol Oral Cir Bucal. 2020;25:e739-44.

23. Pace-Balzan A, Cawood J, Howell R, Lowe D, Rogers S. The liverpool oral rehabilitation questionnaire: a pilot study. J Oral Rehabil. 2004;31:609-17.

24. Rogers S, Forgie S, Lowe D, Precious L, Haran S, Tschiesner U. Development of the International Classification of Functioning, Disability and Health as a brief head and neck cancer patient questionnaire. Int J Oral Maxillofac Surg. 2010;39:975-82.

25. Nazar G, Garmendia ML, Royer M, McDowell JA, Weymuller Jr EA, Yueh B. Spanish validation of the University of Washington Quality of Life questionnaire for head and neck cancer patients. Otolaryngol Head Neck Surg. 2010;143:801-7.

26. Balaguer M, Percodani J, Woisard V. The Carcinologic Handicap Index (CHI): A disability self-assessment questionnaire for head and neck cancer patients. Eur Ann Otorhinolaryngol Head Neck Dis. 2017; $134: 399-403$

27. Rogers SN, Lowe D. An evaluation of the head and neck cancer patient concerns inventory across the Merseyside and Cheshire network. Br J Oral Maxillofac Surg. 2014;52:615-23.

28. Simard EP, Torre LA, Jemal A. International trends in head and neck cancer incidence rates: differences by country, sex and anatomic site. Oral Oncol. 2014;50:387-403. 
29. Fischer DJ, Villines D, Kim YO, Epstein JB, Wilkie DJ. Anxiety, depression, and pain: differences by primary cancer. Support Care Cancer. 2010;18:801-10.

30. Rogers SN, Cross B, Talwar C, Lowe D, Humphris G. A singleitem screening question for fear of recurrence in head and neck cancer. Eur Arch Otorhinolaryngol. 2016;273:1235-42.

\section{Acknowledgements}

The authors would like to thank Laura Clemente (odontologist from La Paz Hospital), who helped us to recruit patients for the study. Our thanks also go out to Centro Superior de Estudios Universitarios La Salle for it support in the English-language edition of this manuscript.

\section{Funding}

Centro Superior de Estudios Universitarios La Salle for funding the English-language edition of this manuscript.

\section{Conflict of interest}

The authors declare that they have no conflicts of interest.

\section{Ethics}

Ethics Committee of La Paz University Hospital. Registration number: PI-1923.

\section{Authors contributions}

Conceptualization, J.P.M and A.G.M; methodology, J.P.M and A.G.M.; formal analysis, J.P.M.; investigation, B.S.G, I.B.R, JM.Z.V, JL.C.C, JL.C.P.V, J.P.M and A.G.M; resources, JL.C.C and JL.C.P.V.; data curation, B.S.G, I.B.R and JM.Z.V.; writing-original draft preparation, B.S.G, I.B.R, JM.Z.V and A.G.M; writing-review and editing, B.S.G and A.G.M.; supervision, A.G.M.; project administration, A.G.M. All authors have read and agreed to the published version of the manuscript. 